\title{
Multiple Intradural Disc Herniations Masquerading as Intradural Extramedullary Tumors: A Case Report and Review of the Literature
}

\author{
Young-Seop Park ${ }^{1}$, Seung-Jae Hyun ${ }^{2}, \mathrm{Ki}-J e o n g \mathrm{Kim}^{2}$, Tae-Ahn Jahng ${ }^{2}$ \\ 'Department of Neurosurgery, Spine Center, Gyeongsang National University Changwon Hospital, \\ Gyeongsang National University Graduate School of Medicine, Jinju, \\ ${ }^{2}$ Department of Neurosurgery, Spine Center, Seoul National University Bundang Hospital, \\ Seoul National University College of Medicine, Seongnam, Korea
}

Intradural disc herniation is a very rare condition, and multiple intradural disc herniations have not been reported to date. The latter may be confused with intradural extramedullary (IDEM) spinal tumors. Here, we report a case of multiple intradural disc herniations masquerading as multiple IDEM tumors and review the relevant literature. We retrospectively reviewed the patient's medical chart, reviewed the intraoperative microscopic findings, and reviewed of PubMed articles on intradural disc herniation. The masses considered to be IDEM tumors were confirmed to be multiple intradural disc herniations. A nonenhancing mass was found to have migrated along the intra-arachnoid space. Two enhancing masses could not migrate because of adhesion and showed peripheral neovascularization. We report an extremely rare case of multiple intradural lumbar disc herniations showing diverse enhancing patterns and masquerading as multiple IDEM tumors. In case of multiple enhancing IDEM masses suspected preoperatively, surgeons should consider the possibility of intradural disc herniation.

Key Words: Intervertebrtal disc displacement $\cdot$ Lumbar vertebrae $\cdot$ Neoplasms

\section{INTRODUCTION}

Intradural lumbar disc herniation was first reported in 1942, and more than 100 cases have been reported since, ${ }^{6,14,20)}$. In cases of intradural disc herniation, surgeons often find it difficult to distinguish between extrusion disc herniation and intradural extramedullary (IDEM) tumors ${ }^{12}$. This confusion can result in failed surgeries or an incorrect diagnosis of an IDEM tumor during surgery. In cases of suspected IDEM tumors, the possibility of intradural disc herniation should be considered if the patient presents with sudden onset back pain and masses located adjacent to a degenerative disc. Multiple masses with different enhancement patterns on magnetic resonance images could also confuse surgeons leading to an incorrect diagnosis ${ }^{2,14}$. Here, we describe an extremely rare case of multiple intradural disc herniations masquerading as multiple IDEM tumors.

- Received: November 3, 2015 • Revised: January 17, 2016

- Accepted: January 18, 2016

Corresponding Author: Ki-Jeong Kim, MD, PhD

Department of Neurosurgery, Spine Center, Seoul National University Bundang Hospital, Seoul National University College of Medicine,

82 Gumi-ro 173beon-gil, Bundang-gu, Seongnam 13620, Korea

Tel: +82-31-787-7166, Fax: +82-31-787-4097

E-mail: kijeong@snu.ac.kr

$\otimes$ This is an open access article distributed under the terms of the Creative Commons Attribution Non-Commercial License (http://creativecommons.org/licenses/by-nc/4.0/) which permits unrestricted non-commercial use, distribution, and reproduction in any medium, provided the original work is properly cited.

\section{CASE REPORT}

A 43-year-old man presented with lower back pain that radiated laterally to his right thigh that had persisted for 3 months. During the previous 6 years, the patient had undergone 3 lumbar spine magnetic resonance imaging (MRI) examinations and 10 sessions of epidural steroid injection for recurrent back pain. His deep tendon reflexes and peripheral circulation had been normal throughout. The last of the 3 MRI examinations had revealed 3 round intradural masses along the second and third lumbar spine, although there were no specific changes in the disc space compared with the previous magnetic resonance images (Fig. 1A). Two of the masses were homogeneously enhanced, while the third was nonenhanced (Fig. 1C). The nonenhanced mass had moved down within the subarachnoid space, as determined by comparison with the images obtained 7 days previously (Fig. 1B). The preoperative diagnosis was multiple IDEM tumors, possibly schwannoma, and surgery was planned.

An L3 partial laminoplastic laminotomy was performed and a durotomy was performed and a durotomy was made, revealing the two enhancing masses. One was a $0.3 \times 0.5-\mathrm{cm}$ yellowish mass located in the dorsal subarachnoid space at the L2-3 disc level and adhered to the cauda equina via vascular proliferation from the nerve roots (Fig. 2A). The second mass was found just inferior to the first (Fig. 2A). Following its separation from the surrounding nerve roots and opening of its cap- 


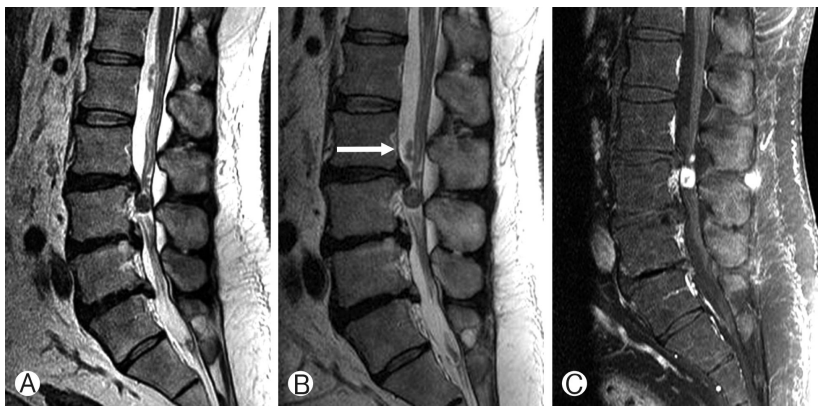

Fig. 1. Preoperative magnetic resonance imaging of the lumbar spine. Compared with previous sagittal T2-weighted image (A), follow-up magnetic resonance image shows migration of mass from the L2/3 to L3/4 level (arrow) (B). (C) The main mass shows near complete enhancement.
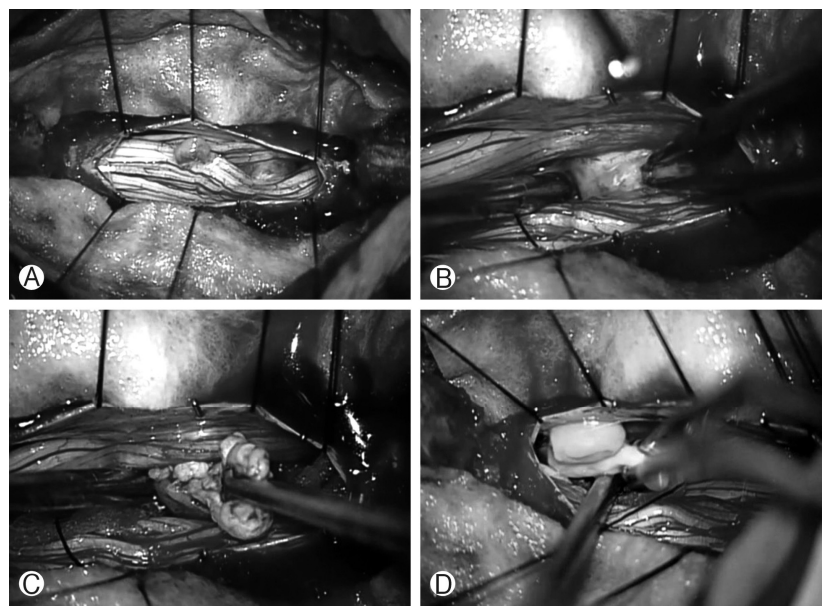

Fig. 2. Intraoperative photographs. (A) After durotomy, 2 masses were found at the L3/4 level. $(\mathrm{B}, \mathrm{C})$ The main mass was removed after coagulation and incision of the surface. (D) The mass that was found to have migrated was detected on exploration of the cauda equina.

sule-like surface, the mass was removed completely (Fig. 2B, C). A frozen section biopsy confirmed that the mass was composed of degenerated disc material. After careful exploration of the cauda equine, the third mass that was found to be nonenhanced and migrating along the cerebrospinal fluid space on MRI was found at the L2/3 level; it was nonvascular and did not adhere to the cauda equina (Fig. 2D). Following surgery, the patient's back and right leg pain improved. Pathological examination of the surgical specimen showed degenerated fibrocartilage, partial capillary proliferation, interstitial edema, and inflammation in parts of the ventral dura mater.

\section{DISCUSSION}

Because of their numerous and various clinical presenta- tions, preoperative diagnosis of intradural disc herniations is very difficult ${ }^{1,7,16)}$. The most commonly associated symptom is acute exacerbation of back pain, although this is not specific for intradural disc herniation. Several pathophysiologic mechanisms of intradural herniations have been postulated. Blikra ${ }^{3)}$ observed anatomic adhesions between the posterior longitudinal ligament (PLL) and dura in a cadaver study. Other studies suggest that previous surgery could increase the risk of intradural herniations ${ }^{5,19)}$. These findings together with presentation in older age contradict the congenital malformation theory ${ }^{5,18)}$.

Contrast-enhanced MRI is the gold standard for the diagnosis of intradural disc herniations ${ }^{7,8}$; however, as in this case, diagnoses are often made during surgery ${ }^{11,13)}$. Despite this, contrast-enhanced MRI is required for the differential diagnosis of spinal IDEM tumors such as schwannomas or meningiomas ${ }^{11,17)}$. Rim enhancement is a typical feature of these tumors and is caused by chronic granulation tissue and/or peripheral neovascularization ${ }^{11)}$. In some cases, rim enhancements of the lesion and PLL discontinuity were found on gadoliniumenhanced $\mathrm{MRI}^{4)}$.

Computed tomography of intradural discs reveal an increased frequency of air densities in the intradural space ${ }^{9,13)}$. Dural perforations can also be observed in the discographies). Myelography is also useful in detecting complete blockage in $71 \%$ of cases of intradural disc herniation ${ }^{1)}$. Of note however, similar imaging findings have been noted in cases of other types of disc herniation as well as IDEM tumors ${ }^{1,10)}$.

Obesity (as in this case); events that rapidly increase intradiscal pressure, such as trauma; history of treatment for lumbar disc disease; and dramatic changes in MRI findings within a short duration are features more likely to be associated with intradural disc herniation than with IDEM tumors ${ }^{15)}$. Although contrast-enhanced MRI is the best modality for diagnosis, in most cases of symptomatic disc herniation, physicians do not have to access to contrast-enhanced MRI. In certain cases of intradural disc herniation, extradural extrusion seems like the most logical diagnosis based on MRI findings ${ }^{4)}$. In this case, if disc material was not found in the extradural space, most surgeons would conclude that the surgical level of the spine was incorrect. If the vertebral surgical level is correct, surgeons should consider the possibility of an intradural disc herniation and, accordingly, intradural exploration should be conducted. However, it is important to check the rupture point of dura matter before intradural exploration ${ }^{13)}$. The anterolateral portion of the dura matter should be inspected because this is a common route for disc migration into the intradural space. If disc material is found, pathological examination should be performed to confirm the diagnosis. Unlike in most cases, we used contrast-enhanced MRI to detect 3 masses at different levels with different enhancement patterns. Intradural disc herniation was difficult to diagnose based on this information. However, the change in position of the nonenhancing mass between the last two MRI examinations was an important indicator of a possible intradural disc herniation. 


\section{CONCLUSION}

We report our experience with an extremely rare case of multiple intradural disc herniations masquerading as multiple IDEM tumors. Even in cases of multiple enhancing IDEM masses diagnosed preoperatively, surgeons should consider the possibility of intradural disc herniation.

\section{CONFLICT OF INTEREST}

No potential conflict of interest relevant to this article was reported.

\section{REFERENCES}

1. Arnold PM, Wakwaya YT: Intradural disk herniation at L1-L2: report of two cases. J Spinal Cord Med 34:312-314, 2011

2. Aydin MV, Ozel S, Sen O, Erdogan B, Yildirim T: Intradural disc mimicking: a spinal tumor lesion. Spinal Cord 42:52-54, 2004

3. Blikra G: Intradural herniated lumbar disc. J Neurosurg 31:676679, 1969

4. Choi JY, Lee WS, Sung KH: Intradural lumbar disc herniation: is it predictable preoperatively? A report of two cases. Spine J 7:111-117, 2007

5. D’Andrea G, Trillò G, Roperto R, Celli P, Orlando ER, Ferrante L: Intradural lumbar disc herniations: the role of MRI in preoperative diagnosis and review of the literature. Neurosurg Rev 27:75-80, 2004

6. Dandy WE: Serious complications of ruptured intervertebral disks. JAMA 119:474-477, 1942

7. Ducati LG, Silva MV, Brandão MM, Romero FR, Zanini MA: Intradural lumbar disc herniation: report of five cases with literature review. Eur Spine J 22 Suppl 3:S404-408, 2013
8. Hida K, Iwasaki Y, Abe H, Shimazaki M, Matsuzaki T: Magnetic resonance imaging of intradural lumbar disc herniation. J Clin Neurosci 6:345-347, 1999

9. Hidalgo-Ovejero AM, García-Mata S, Gozzi-Vallejo S, IzcoCabezón T, Martínez-Morentín J, Martínez-Grande M: Intradural disc herniation and epidural gas: something more than a casual association? Spine (Phila Pa 1976) 29:E463-467, 2004

10. Holtås S, Nordström CH, Larsson EM, Pettersson H: MR imaging of intradural disk herniation. J Comput Assist Tomogr 11: 353-356, 1987

11. Jain SK, Sundar IV, Sharma V, Goel RS, Gupta R: Intradural disc herniation: a case report. Turk Neurosurg 23:389-391, 2013

12. Kim HS, Eun JP, Park JS: Intradural migration of a sequestrated lumbar disc fragment masquerading as a spinal intradural tumor. J Korean Neurosurg Soc 52:156-158, 2012

13. Kobayashi K, Imagama S, Matsubara Y, Yoshihara H, Hirano $\mathrm{K}$, Ito $\mathrm{Z}$, et al: Intradural disc herniation: radiographic findings and surgical results with a literature review. Clin Neurol Neurosurg 125:47-51, 2014

14. Koç RK, Akdemir H, Oktem IS, Menkü A: Intradural lumbar disc herniation: report of two cases. Neurosurg Rev 24:44-47, 2001

15. Lee HW, Kwon YM: Traumatic intradural lumbar disc herniation without bone injury. Korean J Spine 10:181-184, 2013

16. Lee JS, Suh KT: Intradural disc herniation at L5-S1 mimicking an intradural extramedullary spinal tumor: a case report. J Korean Med Sci 21:778-780, 2006

17. Liu CC, Huang CT, Lin CM, Liu KN: Intradural disc herniation at L5 level mimicking an intradural spinal tumor. Eur Spine J 20 Suppl 2:S326-329, 2011

18. Reina EG, Calonge ER, Heriot RP: Transdural lumbar disc herniation. Spine (Phila Pa 1976) 19:617-619, 1994

19. Schisano G, Franco A, Nina P: Intraradicular and intradural lumbar disc herniation: experiences with nine cases. Surg Neurol 44:536-543, 1995

20. Schisano G, Nina P: Intraradicular lumbar disc herniation: case report and review of the literature. Neurosurgery 43:400, 1998 